\title{
Non-homologous sex chromosomes in two species of the genus Eigenmannia (Teleostei: Gymnotiformes)
}

\author{
F. Henning ${ }^{a}$ V. Trifonov ${ }^{b}$ M.A. Ferguson-Smith ${ }^{c}$ L.F. de Almeida-Toledo ${ }^{a}$ \\ a Department of Genetics and Evolutionary Biology, University of São Paulo, São Paulo (Brasil) \\ ${ }^{b}$ Institute of Cytology and Genetics, Russian Academy of Sciences, Novosibirsk (Russia) \\ ${ }^{c}$ Cambridge Resource Centre for Comparative Genomics, University of Cambridge, Cambridge (UK)
}

\begin{abstract}
The Neotropical genus Eigenmannia is a fish group with unknown species diversity where representatives possess a broad range of chromosomal sex determining systems namely $\mathrm{XY} / \mathrm{XX}, \mathrm{X}_{1} \mathrm{X}_{2} \mathrm{Y} / \mathrm{X}_{1} \mathrm{X}_{1} \mathrm{X}_{2} \mathrm{X}_{2}, \mathrm{ZZ} / \mathrm{ZW}$ as well as homomorphic sex chromosomes. To test the homology of two heteromorphic XY sex chromosome systems present in two sympatric populations, reciprocal cross-species FISH experiments were performed using probes de-
\end{abstract}

rived by microdissection of $\mathrm{X}$ and $\mathrm{Y}$ chromosomes present in analyzed specimens of Eigenmannia virescens and Eigenmannia sp.2, respectively. While X and Y paint probes hybridized to species-specific sex chromosomes, in reciprocal cross-FISH both probes hybridized exclusively to autosomes. The result suggests multiple independent origins of the XY systems in the analyzed populations.
Although conserved in groups such as mammals, birds and snakes, chromosomal sex determination systems have evolved independently in most major groups (Matsubara et al., 2006; Vallender and Lahn, 2006; Kawai et al., 2007). Broad-scale phylogenetic character mapping of sex determining mechanisms in Teleostei has revealed that only a minority of orders display a single sex determination system (Devlin and Nagahama, 2002; Mank et al., 2006). This led Mank et al. (2006) to conclude that 'most if not all of the broad categories of sex determination in teleosts had multiple evolutionary origins'. Notably, alternative chromo-

\footnotetext{
Financial support was granted by FAPESP and CNPq. The Cambridge Resource Centre for Comparative Genomics is supported by a Wellcome Trust grant to MAFS.

Request reprints from Lurdes Foresti de Almeida-Toledo

Rua do Matão, 277 Sala 227

Department of Genetics and Evolutionary Biology

São Paulo, SP (Brasil)

telephone: +55 113091 7554; fax : +55 1130917553

e-mail: lftoledo@ib.usp.br
}

some systems can coexist in the same genus (Takehana et al., 2007a, b) and even in the same species of fish (Volff and Schartl, 2001).

The Neotropical weakly-electric eel Eigenmannia comprises a group of unresolved species presenting high diversity of karyotype constitutions and a broad range of chromosomal sex determining systems. In the two major river basins of the state of São Paulo (Brasil), several populations of Eigenmannia virescens bearing different karyotypes have been described, including two populations displaying heteromorphic sex chromosomes. These populations present overlapping distributions that have been referred to as E. virescens $(2 \mathrm{n}=38, \mathrm{XY} / \mathrm{XX})$ and E. sp. $2\left(2 \mathrm{n}=31, \mathrm{X}_{1} \mathrm{X}_{2} \mathrm{Y} / 32\right.$, $\mathrm{X}_{1} \mathrm{X}_{1} \mathrm{X}_{2} \mathrm{X}_{2}$ ) (Almeida-Toledo and Foresti, 2001).

E. virescens $(2 \mathrm{n}=38, \mathrm{XY} / \mathrm{XX})$ possesses an acrocentric $\mathrm{X}$ chromosome with a heterochromatinized distal region highly enriched with GC-rich sequences (Almeida-Toledo et al., 2001). Heterochromatinization has been suggested to play a central role in early instances of sex chromosome differentiation due to effects such as inhibition of recombination and position effect variegation (McKee and Handel, 1993; Hennig, 1999; Griffin et al., 2002). The Y chromosome 
Fig. 1. FISH of sex chromosome probes (a) EVX on a male specimen of E. virescens $(2 \mathrm{n}=$ $38, \mathrm{XY})$ and (c) E2Y on a male specimen of $E$. sp. $2\left(2 \mathrm{n}=31, \mathrm{X}_{1} \mathrm{X}_{2} \mathrm{Y}\right)$. Sex chromosomes are indicated on DAPI counterstained negative images (b and $\mathbf{d}$ ). Note the homology of sex chromosomes $\mathrm{X}-\mathrm{Y}$ in (a) and $\mathrm{Y}-\mathrm{X}_{1} \mathrm{X}_{2}$ in (c). Note also the complex pattern of the X-specific heterochromatin in (b). The heterochromatic q arm of chromosome 8 (following Almeida-Toledo et al., 2001) reproducibly presented hybridization signals and is marked by an asterisk.

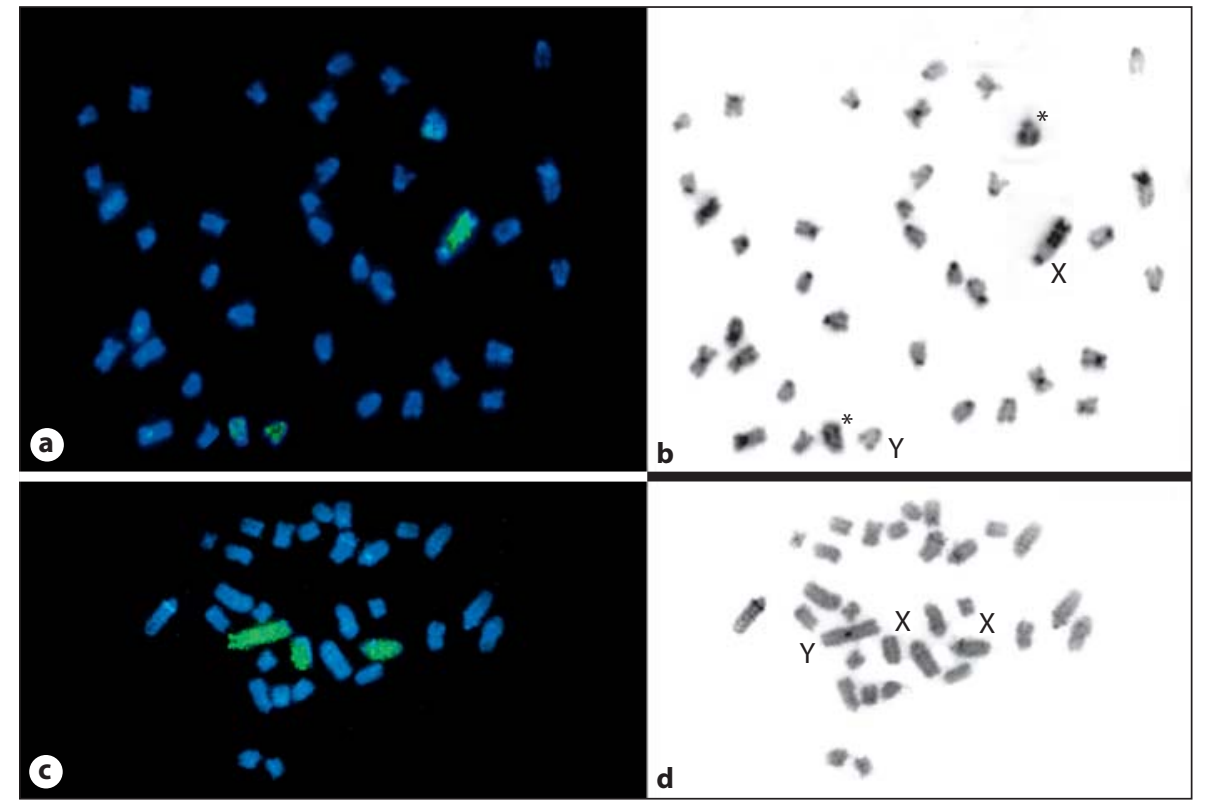

present in the karyotype of E. sp.2 presumably originated from a Y-autosome fusion, as hypothesized by meiotic analysis and BrdU staining (Almeida-Toledo et al., 1988).

Chromosome painting techniques have been applied to fish in only a handful of studies. In all these cases, probes were obtained by chromosome microdissection (Reed et al., 1995; Campos-Ramos et al., 2001; Phillips et al., 2001; Harvey et al., 2002; Liu et al., 2002). Although probes obtained from flow-sorting are better suited for cross-species FISH (Ferguson-Smith et al., 1998), there are several impediments for its use such as the need for chromosomes which present differences in size and base content as well as high quality cell cultures.

In the present study, we assess the hypothesis of independent origins of two different sex chromosome systems (XY/ $\mathrm{XX}$ and $\mathrm{X}_{1} \mathrm{X}_{2} \mathrm{Y} / \mathrm{X}_{1} \mathrm{X}_{1} \mathrm{X}_{2} \mathrm{X}_{2}$ ) present in the karyotype of Eigenmannia virescens and sp.2, respectively, through the use of reciprocal chromosome painting applying sex chromosome-specific probes derived from microdissected chromosomes.

\section{Materials and methods}

\section{Metaphase preparation}

Male and female specimens of E. virescens and E. sp.2 were collected in different small tributaries of the Tietê River, in the municipalities of São Miguel Arcanjo and Indaiatuba, respectively, of the state of São Paulo (Brasil) in 2006. Mitotic chromosome suspensions were prepared directly from kidney tissues as described previously (Almeida-Toledo et al., 2001).

\section{Chromosome microdissection and DOP-PCR}

One copy of the X and four copies of the Y chromosome were microdissected from the karyotype of $E$. virescens (female) and that of $E$. sp.2 (male), respectively using the methodology previously described (Weimer et al., 1999) with minor modifications.
Briefly, chromosomes were dissected from Giemsa-stained coverslips with a micromanipulator (Eppendorf, Germany) attached to a inverted microscope (Zeiss Axiovert 100 or 135) using borosilicate needles prepared with a pipette puller model PB-7 (Narishige, Japan) and transferred to a micropipette containing a collection solution $(1.5 \mu \mathrm{g} /$ $\mu l$ proteinase $\mathrm{K}, 0.1 \%$ SDS, $0.1 \%$ Triton X-100, $1 \mathrm{mM}$ EDTA, $10 \mathrm{mM}$ Tris-HCl, pH 8.0, $10 \mathrm{mM} \mathrm{NaCl}$ ) following Weimer et al. (1999).

Pipette tips were broken in a $0.5 \mathrm{ml}$ microtube containing $5 \mu \mathrm{l}$ of a DOP-PCR (Telenius et al., 1992) mix consisting of dNTPs $(200 \mu \mathrm{M})$, $5 \mu \mathrm{M}$ 6-MW primer (5'-CCGACTCGAGNNNNNNATGTGG-3') and T7 reaction buffer (24 mM Tris- $\mathrm{HCl}, \mathrm{pH} 7.5,12 \mathrm{mM} \mathrm{MgCl}_{2}, 30 \mathrm{mM}$ $\mathrm{NaCl}$ ).

The first eight cycles of DOP-PCR were conducted using T7 DNA polymerase (USB Biochemicals, USA) under the following profile: $1 \mathrm{~min}$ denaturation at $92^{\circ} \mathrm{C}, 2 \mathrm{~min} 20 \mathrm{~s}$ annealing at $25^{\circ} \mathrm{C}$ and $2 \mathrm{~min}$ extension at $34^{\circ} \mathrm{C}$. An initial denaturation step ( $5 \mathrm{~min}$ ) was included to inactivate proteinase. $0.3 \mathrm{U}$ Sequenase was added at each cycle during annealing. Reaction volume was then increased to $50 \mu \mathrm{l}$ containing $0.1 \mathrm{U}$ Taq polymerase and 33 cycles were conducted with the following profile: $1 \mathrm{~min}$ denaturation at $92^{\circ} \mathrm{C}, 2 \mathrm{~min}$ annealing at $56^{\circ} \mathrm{C}$ and 2 min extension at $70^{\circ} \mathrm{C}$ followed by a final 5 min extension step. A detailed description of a DOP-PCR reaction profile can be found elsewhere (Guan et al., 1993; Weimer et al., 1999; Henning et al., in press). Hereafter, we refer to these two probes as EVX (for E. virescens X probe) and E2Y (for E. sp.2 Y probe).

\section{Fluorescence in situ hybridization}

Primary amplification products were re-amplified in 22 additional DOP-PCR cycles catalyzed by Taq polymerase (as described above) in the presence of $0.1 \mathrm{mM}$ biotin-16-dUTP. FISH was performed on chromosome preparations of $E$. virescens and $E$. sp. 2 specimens. The slides were prepared according to Henegariu et al. (2001), pre-treated for 5 min with pepsin $(0.01 \%$ in $10 \mathrm{mM} \mathrm{HCl})$ and aged $\left(60^{\circ} \mathrm{C}\right.$ for $\left.1 \mathrm{~h}\right)$. Slides were denatured in $70 \%$ formamide $/ 0.66 \times \mathrm{SSC}$ for $2 \mathrm{~min}$ at $72^{\circ} \mathrm{C}$. For each slide, $12 \mu \mathrm{l}$ of hybridization solution (containing $0.2 \mu \mathrm{g}$ labeled probe, $50 \%$ formamide, $2 \times$ SSC, $10 \%$ dextran sulfate and $5 \mu \mathrm{g}$ salmon sperm DNA) was denatured for $10 \mathrm{~min}$ at $75^{\circ} \mathrm{C}$ and allowed to prehybridize for $1 \mathrm{~h}$ at $37^{\circ} \mathrm{C}$. Hybridization took place for $72 \mathrm{~h}$ at $37^{\circ} \mathrm{C}$. Slides were then washed at $42^{\circ} \mathrm{C}$ with $50 \%$ formamide/ $1 \times$ SSC, $2 \times$ SSC and $0.2 \times$ SSC for 5-15 min each. Detection was carried out using avidin-FITC (Vector Labs, USA). 


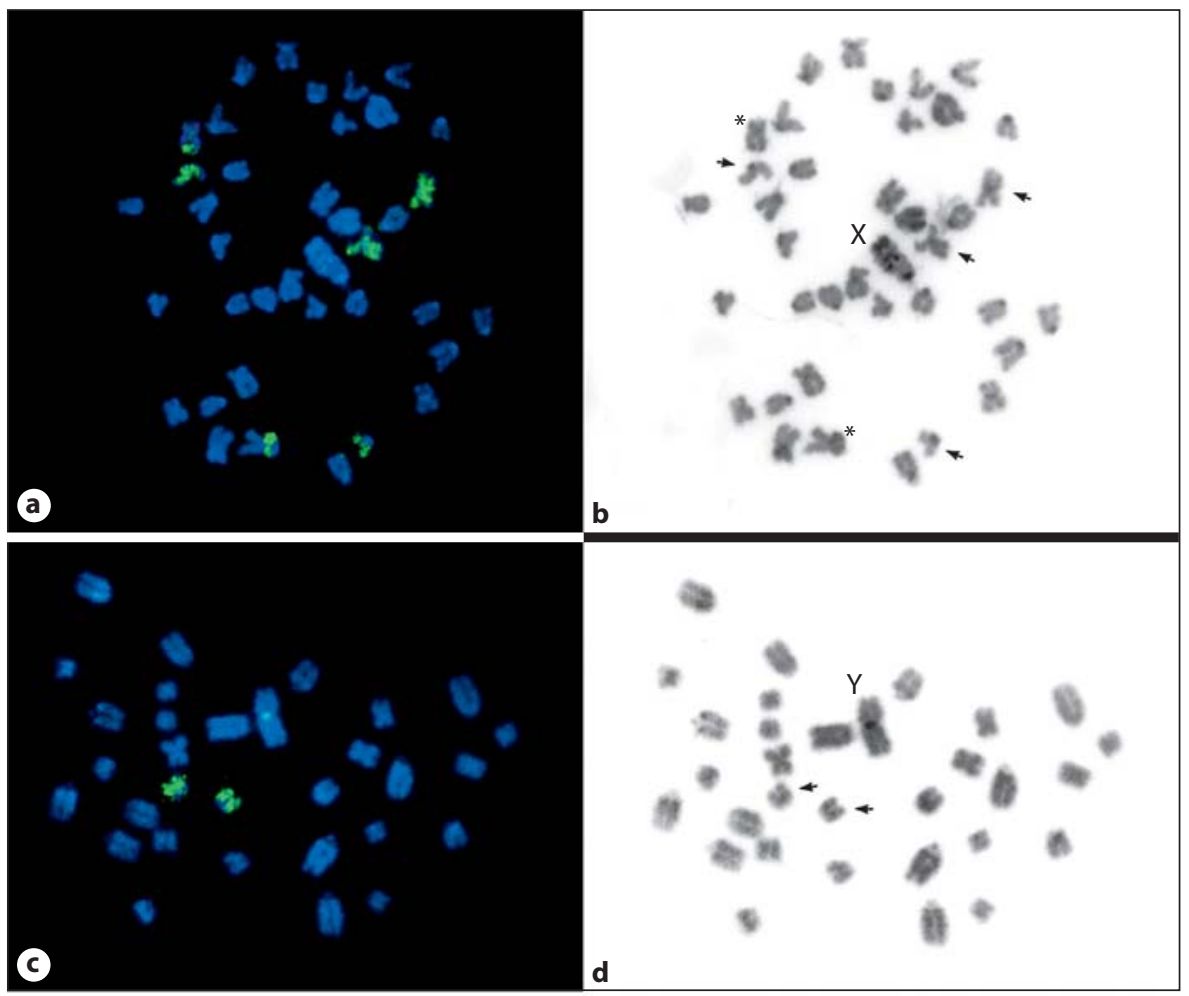

Fig. 2. Cross-species FISH of sex chromosome probes (a) E2Y on a male specimen of $E$. virescens $(2 \mathrm{n}=38, \mathrm{XY})$ and $(\mathbf{c})$ EVX on a male specimen of E. sp.2 $\left(2 \mathrm{n}=31, \mathrm{X}_{1} \mathrm{X}_{2} \mathrm{Y}\right)$. Autosomes displaying hybridization signals are indicated with arrows on DAPI counterstained negative images (b and $\mathbf{d})$. Note that recognizable sex chromosomes lack hybridization signals (large acrocentric in $\mathbf{a}$ and large metacentric in $\mathbf{c}$. Additional signals can be seen in $\mathbf{b}$ in heterochromatic regions of chromosomes 3 and 6 (following Almeida-Toledo et al., 2001) and are marked by an asterisk.

Slides were counterstained and mounted using Vectashield ${ }^{\circledR}$ Mounting Medium with DAPI (Vector Labs) and visualized under an Olympus BX60 fluorescence microscope. FITC and DAPI images were captured separately as 16-bit black and white, colored and mounted using ImagePlus ${ }^{\circledR}$ (Media Cybernetics).

\section{Results}

The X chromosome-specific probe (EVX) obtained by chromosome microdissection hybridized to the $\mathrm{X}$ and $\mathrm{Y}$ chromosomes of the E. virescens karyotype, demonstrating the high level of homology of euchromatic regions of the X and Y chromosomes (Fig. 1a). DAPI counterstaining revealed a complex striped banding pattern on the $\mathrm{X}$ chromosome (Fig. 1b). This is in contrast to the original description of this karyotype, in which the heterochromatic block was found to be DAPI negative (GC-rich) (Almeida-Toledo et al., 2001). A strong hybridization bias towards repetitive sequences was observed, presumably because of the highly heterochromatic distal region of the $\mathrm{X}$ chromosome; this probably resulted in a probe highly enriched with repetitive sequences. Chromosome 8, which also contains a heterochromatic GC-rich region, was consistently painted by this probe.

The probe developed from four copies of $E$. sp.2 Y chromosome (E2Y) hybridized to the $\mathrm{Y}$ chromosome as well as to two acrocentric chromosomes $\left(\mathrm{X}_{1}\right.$ and $\left.\mathrm{X}_{2}\right)$, as shown in Fig. 1c.
Reciprocal cross-species FISH (EVX probe on E. sp.2 karyotype and $\mathrm{E} 2 \mathrm{Y}$ probe on to E. virescens karyotype) resulted in hybridization signals on autosomes (Fig. 2). E2Y hybridized completely to a metacentric pair and a small acrocentric pair. Heterochromatic blocks of chromosomes 3 and 8 were also reproducibly highlighted by E2Y (Fig. 2a). The EVX probe hybridized to a small acrocentric pair (Fig. 2c). None of the distinguishable sex chromosomes displayed consistent hybridization signals after cross-FISH.

\section{Discussion}

The lack of signals on recognizable sex chromosomes after reciprocal cross-species FISH using sex chromosome probes indicates a lack of homology between the $\mathrm{X}_{1} \mathrm{X}_{2} \mathrm{Y} /$ $\mathrm{X}_{1} \mathrm{X}_{1} \mathrm{X}_{2} \mathrm{X}_{2}$ and $\mathrm{XY} / \mathrm{XX}$ systems found in Eigenmannia. Moreover, a previous phylogenetic map of sex chromosome systems based on mtDNA sequences supports the hypothesis of independent origins (Moysés, 2005). Non-homologous sex chromosomes have also been reported in species of Oryzias (Takehana et al., 2007b) and three salmonid genera (Phillips et al., 2001; Woram et al., 2003) and are presumably a widespread phenomenon in fish (Devlin and Nagahama, 2002; van Doorn and Kirkpatrick, 2007).

In the genus Oryzias (Beloniformes), the presence of different sex determining genes in congeneric species implies that multiple loci can assume the role of triggering sex determination (Matsuda, 2005; van Doorn and Kirkpatrick, 2007). On the other hand, the same sex determination re- 
gion is apparently conserved in salmonid species (Salmoniformes) and has evolved through mechanisms of translocation or transposition (Woram et al., 2003). Nonetheless, evidence presented here shows that non-homologous chromosomes bear sex-determining regions in Eigenmannia. Homology of the sex-determining region per se can only be investigated using genetic or high resolution mapping.

Banding pattern obtained with DAPI counterstaining on the $E$. virescens karyotype contrasts to the original description of the X chromosome heterochromatic block (AlmeidaToledo et al., 2001). This demonstrates population-level variability in base composition of the X-specific heterochromatin. Hybridization patterns observed by using the EVX probe support the hypothesis that the $\mathrm{X}$ chromosome in E. virescens differentiated from the $\mathrm{Y}$ chromosome through the accumulation of repetitive sequences on the $\mathrm{X}$ and shares sequences with chromosome 8 . Hybridization of the Y-derived probe (E2Y) to two acrocentric X chromo- somes in E. sp. 2 adds further evidence to the origin by fusion hypothesis concerning the $\mathrm{Y}$ chromosome (AlmeidaToledo et al., 2000).

The remarkable variety of sex chromosomes, sometimes in the same nominal species such as in the unresolved genus Eigenmannia, warrants basal vertebrates as models for understanding early evolution of sex chromosome differentiation (Charlesworth, 2004). The general picture seems to point to a pattern of lack of phylogenetic constraints and multiple independent events (Eggert, 2004; Mank et al., 2006; Quinn et al., 2007).

\section{Acknowledgements}

We thank Dr. Eduardo Gorab (USP) for permitting the use of facilities and equipment, and Dr. Fengtang Yang (Sanger Institute) and the anonymous reviewers for helpful comments.

\section{References}

Almeida-Toledo LF, Foresti F: Morphologically differentiated sex chromosomes in Neotropical freshwater fish. Genetica 111:91-100 (2001).

Almeida-Toledo LF, Viegas-Pequignot E, Foresti F, Toledo-Filho SA, Dutrillaux B: BrdU replication patterns demonstrating chromosome homoeologies in two fish species, genus Eigenmannia. Cytogenet Cell Genet 48:117-120 (1988).

Almeida-Toledo LF, Foresti F, Daniel MF, ToledoFilho SA: Sex chromosome evolution in fish: the formation of the neo-Y chromosome in Eigenmannia (Gymnotiformes). Chromosoma 109:197-200 (2000).

-Almeida-Toledo LF, Foresti F, Pequignot EV, Daniel-Silva MF: XX:XY sex chromosome system with $\mathrm{X}$ heterochromatinization: an early stage of sex chromosome differentiation in the Neotropic electric eel Eigenmannia virescens. Cytogenet Cell Genet 95:73-78 (2001).

-Campos-Ramos R, Harvey SC, Masabanda JS, Carrasco LA, Griffin DK, et al: Identification of putative sex chromosomes in the blue tilapia, Oreochromis aureus, through synaptonemal complex and FISH analysis. Genetica 111:143153 (2001).

-Charlesworth B: Sex determination: primitive Y chromosomes in fish. Curr Biol 14:R745-747 (2004).

Devlin RH, Nagahama Y: Sex determination and sex differentiation in fish: an overview of genetic, physiological, and environmental influences. Aquaculture 208:191-364 (2002).

Eggert C: Sex determination: the amphibian models. Reprod Nutr Dev 44:539-549 (2004).

Ferguson-Smith MA, Yang F, O’Brien PC: Comparative mapping using chromosome sorting and painting. ILAR J 39:68-76 (1998)

Griffin DK, Harvey SC, Campos-Ramos R, Ayling LJ, Bromage NR, et al: Early origins of the $\mathrm{X}$ and Y chromosomes: lessons from tilapia. Cytogenet Genome Res 99:157-163 (2002).

-Guan XY, Trent JM, Meltzer PS: Generation of band-specific painting probes from a single microdissected chromosome. Hum Mol Genet 2: 1117-1121 (1993).
Harvey SC, Masabanda J, Carrasco LA, Bromage NR, Penman DJ, Griffin DK: Molecular-cytogenetic analysis reveals sequence differences between the sex chromosomes of Oreochromis niloticus: evidence for an early stage of sexchromosome differentiation. Cytogenet $\mathrm{Ge}$ nome Res 97:76-80 (2002).

- Henegariu O, Heerema NA, Lowe Wright L, BrayWard P, Ward DC, Vance GH: Improvements in cytogenetic slide preparation: controlled chromosome spreading, chemical aging and gradual denaturing. Cytometry 43:101-109 (2001).

- Hennig W: Heterochromatin. Chromosoma 108: 1-9 (1999).

Henning F, Trifonov VA, Almeida Toledo LF: Use of chromosome microdissection in fish molecular cytogenetics. Gene Mol Biol (in press).

Kawai A, Nishida-Umehara C, Ishijima J, Tsuda Y, Ota H, Matsuda Y: Different origins of bird and reptile sex chromosomes inferred from comparative mapping of chicken Z-linked genes. Cytogenet Genome Res 117:92-102 (2007).

Liu JD, Yi MS, Zhao G, Zhou F, Wang DQ, Yu QX: Sex chromosomes in the spiny eel (Mastacembelus aculeatus) revealed by mitotic and meiotic analysis. Cytogenet Genome Res 98:291297 (2002).

Mank JE, Promislow DEL, Avise JC: Evolution of alternative sex-determining mechanisms in teleost fishes. Biol J Linn Soc Lond 87:83-93 (2006).

Matsubara K, Tarui H, Toriba M, Yamada K, Nishida-Umehara C, et al: Evidence for different origin of sex chromosomes in snakes, birds, and mammals and step-wise differentiation of snake sex chromosomes. Proc Natl Acad Sci USA 103:18190-18195 (2006).

Matsuda M: Sex determination in the teleost medaka, Oryzias latipes. Annu Rev Genet 39:293307 (2005).

McKee BD, Handel MA: Sex chromosomes, recombination, and chromatin conformation. Chromosoma 102:71-80 (1993).

Moysés CB: Diversidade genética, estrutura populacional e análises filogenéticas no gênero $E i$ genmannia (Pisces: Gymnotiformes): Departamento de Genética e Biologia Evolutiva, pp 221 (Universidade de São Paulo, São Paulo 2005).
Phillips RB, Konkol NR, Reed KM, Stein JD: Chromosome painting supports lack of homology among sex chromosomes in Oncorhynchus, Salmo, and Salvelinus (Salmonidae). Genetica 111:119-123 (2001).

Quinn AE, Georges A, Sarre SD, Guarino F, Ezaz T, Graves JA: Temperature sex reversal implies sex gene dosage in a reptile. Science 316:411 (2007).

Reed KM, Bohlander SK, Phillips RB: Microdissection of the $\mathrm{Y}$ chromosome and fluorescence in situ hybridization analysis of the sex chromosomes of lake trout, Salvelinus namaycush. Chromosome Res 3:221-226 (1995).

Takehana Y, Demiyah D, Naruse K, Hamaguchi S, Sakaizumi M: Evolution of different Y chromosomes in two medaka species, Oryzias dancena and O. latipes. Genetics 175:1335-1340 (2007a).

- Takehana Y, Naruse K, Hamaguchi S, Sakaizumi $\mathrm{M}$ : Evolution of ZZ/ZW and XX/XY sex-determination systems in the closely related medaka species, Oryzias hubbsi and O. dancena. Chromosoma 116:463-470 (2007b).

- Telenius H, Carter NP, Bebb CE, Nordenskjold M Ponder BA, Tunnacliffe A: Degenerate oligonucleotide-primed PCR: general amplification of target DNA by a single degenerate primer. Genomics 13:718-725 (1992).

-Vallender EJ, Lahn BT: Multiple independent origins of sex chromosomes in amniotes. Proc Natl Acad Sci USA 103:18031-18032 (2006).

van Doorn GS, Kirkpatrick M: Turnover of sex chromosomes induced by sexual conflict. $\mathrm{Na}$ ture 449:909-912 (2007).

Volff JN, Schartl M: Variability of genetic sex determination in poeciliid fishes. Genetica 111:101110 (2001).

Weimer J, Kiechle M, Senger G, Wiedemann U, Ovens-Raeder A, et al: An easy and reliable procedure of microdissection technique for the analysis of chromosomal breakpoints and marker chromosomes. Chromosome Res 7: 355-362 (1999)

-Woram RA, Gharbi K, Sakamoto T, Hoyheim B Holm LE, et al: Comparative genome analysis of the primary sex-determining locus in salmonid fishes. Genome Res 13:272-280 (2003). 